\title{
A speeded-up plan to spread the wealth
}

\section{Paris}

THE French government has accelerated plans to decentralize its research establishment by announcing the transfer over the next three years of more than 2,500 researchers from Paris to regional centres. An additional 2,000 scientists will leave the capital by the end of the decade as part of an effort by the government to distribute public-sector jobs across the country.

The purpose is both to loosen the iron grip of Paris over the conduct of research and to stimulate regional development. Although the greater Paris area, known as the lle de France, contains less than a fifth of the country's population and only a quarter of its student population, it accounts for more than half of the research sponsored by the government.

The decentralization will be felt by all research agencies. In particular, the Centre National de la Recherche Scientifique (CNRS), the nation's major research organization, is to transfer some 2,700 staff to various regional centres by the end of the decade. That shift will reduce the proportion of its staff in Paris from 52 per cent at present to only 40 per cent by 2000 . The cost has been estimated at FF1,300 million (US\$220 million). CNRS officials say that the shift will improve research and that they will not "decentralize for the sake of decentralization".

The scientific community has so far reacted positively, in contrast with the protests that have accompanied similar transfers in the past. Images of the en- forced deportation of unhappy masses of white coats have faded, replaced by the recognition that the changes will be more subtle.

Nearly two-thirds of the new positions are expected to be filled by the movement of individual scientists to existing research establishments elsewhere. In most of the remaining cases, according to officials, researchers will have the chance to build their own teams by moving into new or remodelled and expanded institutions.

Although some of the dislocations will be jarring, Martine Bentaboulet, assistant director of regional development at the CNRS, says that the closing of laboratories in Paris and the forced transfer of their staffs "will occur only in a minority of cases". The CNRS says that it is still discussing which laboratories will be closed.

The stepped-up plans to decentralize French research follows on a deliberate effort to encourage growth outside Paris. For several years, the CNRS has allocated two positions to the regions for every one in the capital. Although officials argue that admission is still based on scientific merit, researchers have complained that candidates willing to set up shop in regional centres have received preference over those who wish to work in Paris. And the application form for admission to the CNRS requires candidates to nominate regional laboratories for two of their three choices.

In 1990, the CNRS extended its decentralization policy beyond staffing to the

\section{India questions Venezuelan data}

\section{New Delhi}

A PUBLISHED report from Venezuela that questions the effectiveness of an anti-leprosy vaccine has stirred debate in India about the fate of an extensive clinical trial using the vaccine. Although some Indian specialists believe that the trial, sponsored by the World Health Organisation (WHO), should be halted, the government says that last month's report in Lancet (339, 446-50; 1992 ) is not relevant to India and that the ongoing trial will continue.

"Obviously the WHO vaccine is of no use to India", says Mahadev Deo, director of the Cancer Research Institute (CRI) in Bombay. "Continuation of the trial would be unethical."

But officials from the Indian Council of Medical Research (ICMR) say that the differing epidemiology and geographical variation in mycobacteria in Venezuela could affect the efficacy of the vaccine. "We don't know if the vaccine will succeed in India", says S.P. Tripathy, chief of the council. "But we cannot stop the trial allocation of resources for new laboratories. That year the Institute of Biology and the Institute of Microelectronics were created in Lille, followed in 1991 by the Institute of Particle Physics in Marseilles and the Institute of Structural Biology in Grenoble. This year a materials laboratory will be built in Bordeaux, and the Maison des Sciences de l'Homme in Toulouse. Each of the new centres reserved space for new research teams from the outside.

Government officials concede that the plan cannot be successful without support from researchers. The improvement of living and working conditions is essential to entice people to leave Paris. Researchers will want proof that the new laboratories are well-equipped, that there are opportunities for promotion and that the overall scientific environment is sound. And there must also be acceptable housing, good schools and job opportunities for spouses.

It is too early to know whether the government will have the resources to carry out its ambitious plan. An agreement last autumn created a special fund for researchers, but so far the fund is empty.

The decentralization plan rests on the concept of creating research 'poles'. Such poles are loose federations of laboratories within a region that, together with local universities and industry, provide a critical mass of research. The CNRS hopes to conduct half of its regional research at seven such centres, with the rest of its funding spread over 16 cities and towns. Putting mathematicians in the MarseilleLuminy area, as well as in Nice, Bordeaux and Lyons, is expected to strengthen interaction with physicists, computer scientists and mechanical engineers in those areas. Similarly, physicists, chemists and biologists will coexist at the Institute for Structural Biology in Grenoble, as well as at similar centres in Marseilles and Montpellier.

There will also be a shift within the Ile de France itself from the centre of Paris towards the outskirts. For example, installations in the humanities and social sciences will be closed, and an archaeology facility and a science centre will be built in Nanterre and Marne la Vallé.

The decentralization will also affect the CNRS administration. In 1990, 12 regional councils were created to work with local authorities, and a staff of 1,070 scattered around seven sites in Paris will be trimmed to 700 and consolidated at one site. More than 200 administrators who direct interdisciplinary programmes will be shifted to the regions, and about 100 will return to the laboratory. In 1995, the entire staff of the Institut Information Scientifique et Technique (INIST) will be transferred to Nancy in the east.

David Bakewell 